\title{
The Method of Equipment Average Replacement TimeVerification Based on Virtual Simulation
}

\author{
WU Xi \\ Department of Arms Engineering, \\ Academy of Armored Force Engineering, \\ Beijing, China, \\ 1113609446@qq.com; \\ WANG Bao-qi \\ Department of Arms Engineering, \\ Academy of Armored Force Engineering, \\ Beijing, China, \\ 283009953@qq.com
}

\begin{abstract}
Aiming to lack for the verification method of equipment maintainability quantitative requirements, this paper researched the verification method of average replacement time through virtual simulation technology, and proposed the mathematical model of average replacement time, which can lay the foundation for maintainability virtual verification.
\end{abstract}

Keywords-virtual Simulation; the average replacement time; verification; fasteners

\section{INTRODUCTION}

The equipment average replacement time is an important indicator of the quantitative requirements of the maintainability; it directly affects MTTR. At present lacking for the verification method of average replacement time, for using of virtual simulation technology, there was not an appropriate verification method.

In the design stage of the equipment, verifying equipment average replacement time cannot be carried out because lacking for a physical prototype. The study on the virtual simulation technology for verification method of the average replacement time has important practical significance to improve equipment maintainability.

\section{Average Replacement Time Virtual Verification PROCESS}

The equipment average replacement time the mainly refers to the summation of equipment disassembly and installation time. The verification of average replacement time based on the virtual conditions should be determined the repair parts, CAD data is imported into the virtual simulation environment after model simplification, which should delete little or no relationship with the disassembly data or model lightweight. In order to make the simulation as realistic as possible, it need select the appropriate percentile virtual human model. The simulation platform includes fasteners model database, the maintenance therblig database and standard time database. Through transfer maintenance therblig database by virtual human detachable
XU Da

Department of Arms Engineering, Academy of Armored Force Engineering, Beijing, China,

MU Ge

Department of Equipment Command and Administration, Academy of Armored Force Engineering, Beijing, China

members disassembly job, completed a complete disassembly simulation, the system will calculate the average replacement time of the components, as shown in Figure 1.

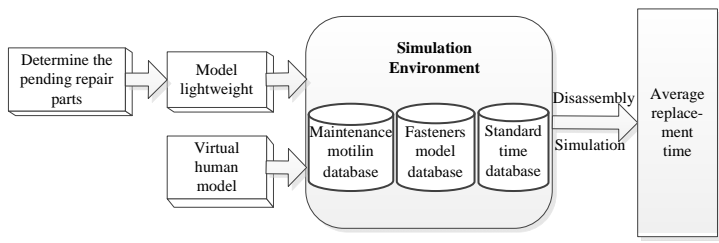

Figure 1 Average Replacement Time Virtual Verification Process

Maintenance therblig decomposition is to identify each part operations constituted by which basic movements of the human body. Using the MOD method calculated the parts basic disassembly operation time, which need to determine composing each basic disassembly operation of the human body (a finger or the arm movement, rotation, etc.). Composing of each disassembly operation body basic movements can be determine by tool simulate disassembly operation $^{[2]}$.

\section{Study ON THE AVERAge RePlacement Time VIRTUAL VERIFICATION METHOD}

\section{A. validation model}

In virtual environment the sources of parts repair time data with the same as MTTR. It completed replacement task simulation by transferred action model database. The system automatically generated disassembly and assembly time through the basic maintenance action model database and the corresponding standard time database. Different to MTTR, the each of the replacement time in specified part is fixed values, which in the case of other factors are not changed.

At actual equipment maintenance, average replacement time composed of parts disassembly time and assembly time. Generally disassembly and assembly of the mutually-inverse 
process, but only in the repair process is similar, the time the two are not identical, and need to be considered separately, obtained replacement time by adding. Average replacement time is synthesized by average disassembly time and average assembly time.

Mathematical model for the average replacement time $(\bar{T})$

$$
\bar{T}=\sum_{i=1}^{n} \bar{t}_{i}+\sum_{j=1}^{m} \bar{t}_{j}
$$

Where $\mathrm{i}$ and $\mathrm{j}$ are the required numbers of therblig by the completion of parts disassembly and assembly, $\bar{t}_{i}$ is the average time needed for the completion of the $i$-th disassembly therblig, $\bar{t}_{j}$ is the average time needed for the completion of the $j$-th assembly therblig. Based on the idea of maintenance therblig decomposition, disassembly and assembly task decomposition to the bottom is the fasteners disassembly therblig, $\bar{t}_{i}$ and $\bar{t}_{j}$ are correspond to fasteners disassembly and assembly time. Therefore, the verification of equipment average replacement time key is statistics the equipment fasteners disassembly and assembly operation time.

\section{B. Determine Impact Factors}

Processing and analysis of equipment maintenance operation statistics, disassembly operation time of the fasteners is the mostly factor in machinery products, which accounting for more than $80 \%$ of the time the entire equipment replacement job. Therefore, analyzing fasteners replacement time data, and study on the rule of various forms of fasteners replacement time, which plays a vital role for validation average replacement time. In order to facilitate the research questions, this paper will fastener disassembly process is divided into three phases:

- unlocking, is that freed locking device;

- threaded coupling separation

- remove, remove the bolts, nuts, screws

The assembly process is the contrary. The three phases of time is fasteners disassembly or assembly time. Seen by the analysis of the three phases, unlock or lock time was reflect infection degree of locking mode disassembly and assembly, which showing the locking of fastener is one of the infection factor in fastener disassembly and assembly time. Separation and installation time of the threaded coupling was impacted by the structure of the fastener itself dimensions and fasteners in which the spatial position environment. Remove the stage time, mainly due to the environmental impact of the spatial location. After comprehensive analysis summarized affect fastener disassembly and assembly time:

- Connection type: Couplings fastening methods, typical fastener join type were bolt connection, stud connection and screw connection;

- The fastener specifications: nominal diameter of fasteners, for short specifications;

- Locking type: in various of connection type, the mechanical stop to prevent the loosening of coupling member, the locking type were elastic washers, lock washers, cotter pins and wire;
- The fastener working length: Loosen the coupling member, the screw or nut need go through a maximum length of the thread, which not contain the thickness of the locking device, for short the working length;

- tool once turn angle when disassembly and assembly: Once twist fasteners, the maximum angle of the tool can be rotated, generally above at $60,90,120$ and 180 to be divided, using sleeve wrench can be recorded as 180 or more, for short the twist angle;

- The degree of difficulty when remove or mount fasteners : The degree of difficulty when the fastener is removed from the installation position or mounted to the prescribe position, divided into easy, usually, difficulties, for short the degree of difficulty.

\section{Fasteners Disassembly and Assembly Time Prediction Model}

According to equipment maintenance work's structural features, combined with the constraints equipment maintenance and many other factors. The operating time calculation model is using regression analysis method. As in many of the factors in the operation process for the fastener, such as unlocked, threaded connection, the separation process, the torsion angle, the operator twisting speed can be assumed to be uniformly constant, doesn't vary with time change. It can be used multiple linear regression equation as the mathematical model, the process is usually:

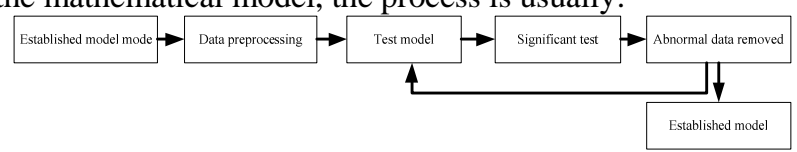

Figure 2 the process of establishment the regression model

In the Figure 2 showed form test model to abnormal data removed is a cyclic process, when established model via significance test that the model is correct, if not pass the significance test, it need to remove the abnormal data, and then re-create the model, until the model created through the significance test, and the parameters in the model can be through significant test so far.

The main factors affect the fasteners disassembly and assembly time are specifications; length of work; turn angle; connection type; locking and the degree of difficulty. To join type classification modeling total of screws, bolts and studs, classification modeling by disassembly and assembly time, it need to establish six models. Each factor as a parameter, the parameter name and code are shown in Table 1.

TABLE I. PARAMETER NAME AND CODE

\begin{tabular}{|c|c|c|c|c|c|c|c|}
\hline $\begin{array}{c}\text { Para- } \\
\text { meter } \\
\text { name }\end{array}$ & $\begin{array}{l}\text { Specif- } \\
\text { ication }\end{array}$ & $\begin{array}{l}\text { Loc- } \\
\text { king }\end{array}$ & $\begin{array}{l}\text { Work- } \\
\text { ing } \\
\text { length }\end{array}$ & $\begin{array}{l}\text { Wren- } \\
\text { ching } \\
\text { angle }\end{array}$ & $\begin{array}{l}\text { Degree } \\
\text { of diffi } \\
\text {-culty }\end{array}$ & $\begin{array}{l}\text { Disass- } \\
\text { embly } \\
\text { time }\end{array}$ & $\begin{array}{l}\text { Asse- } \\
\text { mbly } \\
\text { time }\end{array}$ \\
\hline $\begin{array}{c}\text { code } \\
\text { name }\end{array}$ & $\mathrm{X}_{1}$ & $\mathrm{X}_{2}$ & $\mathrm{X}_{3}$ & $\mathrm{X}_{4}$ & $\mathrm{X}_{5}$ & $\mathrm{Y}_{1}$ & $\mathrm{Y}_{2}$ \\
\hline
\end{tabular}

Consider using multiple linear model fitting: 
$Y=\beta_{0}+\beta_{1} \times X_{1}+\beta_{2} \times X_{2}+\beta_{3} \times X_{3}+\beta_{4} \times X_{4}+\beta_{5} \times X_{5}+\varepsilon$ Using the least squares method to obtain the parameters: $\beta_{0}, \beta_{1}, \beta_{2}, \beta_{3}, \beta_{4}, \beta_{5} \quad$ least squares estimation $b_{0}, b_{1}, b_{2}, b_{3}, b_{4}, b_{5}$, and then obtains the regression equation:

$$
\hat{Y}=b_{0}+b_{1} \times X_{1}+b_{2} \times X_{2}+b_{3} \times X_{3}+b_{4} \times X_{4}+b_{5} \times X_{5}
$$

After collection, statistics, collation, analysis of more than 40,000 fasteners disassembly and assembly data, after removing the abnormal data as follows: One way is to choose a set of data which the same specifications 、 working length and wrenching angle were calculated mathematical expectation of its disassembly and assembly time, and then calculated the mean ratio of different locking mode or degree of difficulty, it can determine the weights value of the various locking mode and degree of difficulty. Another method is using expert scoring method, pair comparison scoring by a number of experts according to the degree of influence in different items, and finally processed statistically different weights value. Eventually fasteners disassembly and assembly time is established model, the model is as follows:

Screw coupling model:

$Y_{1}=0.05644+0.615599 X_{1}+14.933847 X_{2}+0.316332 X_{3}-0.110719 X_{4}$

$Y_{2}=1.924202+0.660327 X_{1}+17.444242 X_{2}+0.331314 X_{3}-0.121351 X_{4}$

Bolt connection model

$Y_{1}=-11.990437+0.995572 X_{1}+27.151115 X_{2}+0.586891 X_{3}-0.048896 X_{4}$

$Y_{2}=-33.956909+0.601069 X_{1}+51.356518 X_{2}+1.414035 X_{3}-0.067999 X_{4}$

Stud coupling model

$Y_{1}=-34.424469+0.615599 X_{1}+24.20212 X_{2}+1.607837 X_{3}-0.010249 X_{4}$

$Y_{2}=-43.890617+0.982267 X_{1}+33.279888 X_{2}+3.137812 X_{3}-0.027221 X_{4}$

\section{CONCLUSION}

Based on the fasteners disassembly and assembly time mathematical model, it can establish standard time database of fasteners disassembly and assembly, which can create different types of screws, bolts, studs through import locking, working length, turn angle data information, and can correspond to the time of different fasteners disassembly and assembly. Through equipment maintenance task simulation under the virtual environment, it was transfer basic maintenance action model database and its corresponding standard time database, which calculating the different fasteners disassembly and assembly time, then gained the average replacement time of the components.

\section{REFERENCES}

[1]LIU Mingzhou, HU Zhen, GUO Jia. Application of MOD method in virtual manufacturing environment[J]. Mechanical Engineer, 2005(4): 56-58.

[2]SUN Youchao, HUANG Jinyong, WANG We. Quantitative Evaluation Method of Product Disassembly Based on Parts Failure Rate and Disassembly Time[J]. JOURNAL OF MECHANICAL ENGINEERING, 2010, 46(13): 147-154.

[3]Yu Xiaohong, Zhang Zhenming. Tian Xi. et. Al. Method of calculating assistant mechanical time based on MOD[J]. Machinery\&Electronics. 2009 (4): 68-71. (in Chinese)

[4]Evan Drumwright, Victor Ng-Thow-Hing, Maja Mataric. The task matrix: An extensible framework for creating versable humanoid robots[C]. Florida: Proc. of the 2006 IEEE Intl. Conf. on Robotics and Automation(ICRA), 2006: 448-455.

[5] AD0906235-Maintainability Demonstration Report for the APD-10 Radar Mapping Set. 